(REVIEW ARTICLE)

\title{
Drivers of the various stands on the debate on GM crops: What are the real motives beyond the public rhetoric?
}

\author{
Zakaria Hudu * \\ Department of Agricultural Extension, Rural Development \& Gender Studies, Faculty of Agribusiness \& Applied \\ Economics, University for Development Studies. Box 1882 Tamale, Ghana.
}

Publication history: Received on 06 February 2020; revised on 25 February 2020; accepted on 28 November 2020

Article DOI: https://doi.org/10.30574/gscarr.2020.2.3.0009

\begin{abstract}
The underlying constructs characterising the never-ending debate and lack of consensus on food are largely issues relating to potential risks and uncertainty GMOs might pose to human health and the environment, and the possible threats to national food sovereignty. This paper is a review study and as such relied solely on published literature on contentious issues surrounding GM crops and its food derivatives. Most of the issues raised in available literature against GMOs on the grounds of health and environmental risks, and national food sovereignty concerns are overhyped, speculative and fear-mongering. Public interest and safety will be better assured and safeguarded if GMOs proponents and opponents reached consensus on standardization regarding tolerable level of harm and acceptable safety limit in interpreting impact assessment results of GMOs on health and environment.
\end{abstract}

Keywords: GM crops; GM food; GM debate; Biosafety and food sovereignty

\section{Introduction}

In the history of crop improvement, the introduction of Genetically Modified (GM) crops had been the most controversial plant breeding techniques in contemporary agricultural research and development. Even in it's over two decades of commercialization consensus are yet to be reached on the appropriateness and safety of Genetically Modified Organisms (GMOs) and its food derivatives. The debate is largely relates to issues of potential health and environmental risks [1,2,3] and concerns relating to 'national food sovereignty' and threat of 'food colonialism' [4, 5]. However, global production of GM crops continues to increase significantly since its first commercialization in 1996 [2]. Within a span of 23 years (from 1996 to 2018), global cultivation of GM crops had spiraled more than 100-folds, reaching 191.7 million hectares in 2018 from just 1.7 million hectares in 1996 [2]. In its 23 years history GM crop have experienced unprecedented high adoption rate increasing every single year with double digit growth rates, except 2015 [6, 7]. In 2018 twenty-six (26) countries comprised of 21 developing and 5 industrialized countries planted a total of 191.7 million hectares of GM crops [6, 2] increasing by 1.9 million hectares compared with the 189.8 million hectares cultivated in 2017 [8].

This remarkably level of adoption of GM crops had never been witnessed in crop technology adoption history in recent times. Within the period of 23 years an accumulated 2.5 billion hectares or 6.3 billion acres were put under GM crops cultivation across developing and industrialized countries by both small and large scale farmers [6, 2]. This development has yielded considerably agronomic and socioeconomic benefits to both small and large scale farmers who have adopted this novel crop technology and had further delivered substantial environmental and health benefits to humanity $[1,9,7,3]$.

\footnotetext{
* Corresponding author: Zakaria Hudu
} 
The increasing trend of adoption and cultivation of GM crops, in the face of mounting anti - GM campaigns, bears amply testimony to the unflagging farmers' and consumers' confidence on the technology and a reflection of the substantial multiple benefits realized from continue adoption and cultivation of GM crops.

However, what is of great concern is the apparent lack of consensus on health, environmental, food security and economic benefits of GM crops. It appears the scientific community had neither adequately addressed public concerns about GM crops and its food derivatives nor effectively communicated the value of this technology to gain public acceptance, which is essential to the continued development and application of biotechnology in commercial agriculture. As results, the general public is not well-informed with the true and holistic picture characterizing the various views and arguments on the safety and appropriateness of this technology in food and feed production.

The apparent lack of scientific information about GMOs in the public domain is worrying, considering the fact that the mass media is an important driver of public opinion on GMOs [4, 10]. Anti - GM activists have understood this and are taking to the media to advance their campaign against GM crops and food. Glaab \& Partzsch [4] looks at the construction of utopian and apocalyptic narratives in social movement campaigns and how they contribute to the construction of identities in the campaigns against GM food and Bt cotton in India and concluded that "organic food" and "ethical cotton" products would be less successful without the concurrent use of apocalyptic narratives on media about GM food and Bt cotton. As a result it is difficult to know where scientific evidence ends and where dogmatism, indoctrination and conjectures begin. Because the mass media is inundated with all kinds of information and misinformation about GMOs.

This paper therefore sought to examine available literature highlighting various issues opponents of GM crops have argued on and juxtaposing them against empirical scientific evidence proponents of GM crops have presented in refuting those arguments. The review sought to contextualize and synchronize the debate with the view of understanding the real motives driving the various positions on the debate and to establish whether those positions are grounded in validated scientific evidence.

The need for this review is premised on the fact that, the mounting challenge against GM crops continue to shape public opinion [11] notwithstanding the fact that there exist considerable scientific consensus that the transgenic foods and crops currently on the market have brought no scientific validated new harmful effects or risks either to human health or to the environment [12].

\section{Methodological approach}

This article reviews scientific literature on GM crops focusing on peer reviewed scientific articles and published evaluation reports on the debate of GM crops and commercialization of biotechnology in agriculture. The review analyses peer-reviewed papers and evaluation reports identified through internet based Web searches (mainly Googlescholar and online academic repositories). These sources of scientific literature have been relied on in many review studies on GM crops and commercialization of agrobiotechnology in general $([1,13,14,3]$. A review study by Mampuys \& Brom [13] on Governance strategies for responding to alarming studies on the safety of GM crops and Pearsall [14] review on GM crop co-existence both employed this approach of internet Web based searches in gathering information for their reviews.

Information which were sought for in the literature were issues of contention regarding GM crops, such as health and environments concerns, arguments relating socioeconomics, food sovereignty and political economy and harmonization of international trade of commodities containing GM products. Also information regarding findings of impact and risk assessments conducted on GM crops and products, regulatory frameworks and standards regarding production, transfer and marketing of GM products were also sought for and analysed with the view of understanding how proponents and anti-GM activists have interpreted and use these findings to advance their augments.

\section{Review results}

This paper is purely a review study, as such literature on various arguments for and against GM crops are examined with the view of understanding the various narratives underpinning the debate on the safety and appropriateness of GM crops. This section presents review and discussion of the various contentious issues regarding the safety and appropriateness of GM crops. 


\subsection{Health and environmental risks arguments}

In order to analyse the debate on possible health and environmental risks of GM crops, this paper adopted the recommendations of European Union Academies Science Advisory Council (EASAC) policy report on GM crops [15]. The policy report observed that the GM debate had suffered from several conceptual problems and lack of standardization in interpreting impact assessment results. The EASCA [15] underscored the following issues on the on-going GM debate:

- Confusion of GM crop effects with effects caused by agricultural practices per se

- Lack of definition of 'harm'

- GM crops need to be incorporated with other agricultural practices

\subsubsection{Confusion of GM crop effects with effects caused by agricultural practices per se}

Agricultural practice in general has profound effect on the environment and biodiversity. Therefore to bring clarity to the debate on the effect of gene modification on the environment is to clearly isolate GM induce effect from the effects caused by general agricultural practice. Because, as a matter of fact, every agricultural practices causes certain changes to the environment, such as deforestation, land degradation, pollution, loss of biodiversity among others. Qaim [16] also bemoaned the lack of clarity associated with the GM debate as it has to do with uncertainty regarding occurrence, timing, attribution and isolated effects, magnitude and significant levels of adverse effects specifically caused by GMOs.

The most hotly debated issues about GMOs, perhaps is issues relating to the safety of GM crops and its food derivatives and potential environment risks and loss of biodiversity. The thumb card of anti-GMO advocates is the argument that genetic modification could lead to possible health conditions such as allergic reaction, carcinogenic and toxicity [13, 16, 3]. Biden, Smyth \& Hudson [17] observed that often the debate against commercial released of biotechnology and GM crops is so fixated on perceived health risks and negative impacts on the environment and biodiversity.

In isolating the effects of gene modification on the environment, recent environmental impact assessments focused on changes in pesticide use and greenhouse gas emissions arising from the use of GM crops $[17,9,18]$. In many of such impact assessments, investigators focused on examining changes in the amount of insecticides and herbicides applied to the GM crops relative to conventionally grown alternatives. And the contribution of GM crops towards reducing global Greenhouse Gas (GHG) emissions compared with their conventional alternatives.

Findings of many independent environmental impact assessments of commercial released of GM crops found no significant adverse effect on the environment in comparison with conventional agriculture. Biden et al. [17] in their study on the economic and environmental cost of delayed GM crop adoption in Australia found that GM canola pose no significant difference in effects on the environment when compared to non-GM canola. They concluded that there were no adverse effects in the five main environmental impact assessment categories (weediness, gene flow, plant pest, non-target organisms and biodiversity) in comparison with non-GM canola.

Notwithstanding the rigorous scientific safety standard and tests that GM crops and its food derivatives are subjected to anti-GM campaigners still sought to link GM foods to health conditions such as cancers, allergic conditions and toxicity. The lack of methodological clarity and certainty in alarming studies linking the consumption of GM food to health risks and harmful effects is not helping the cause of scientific consensus needed to ensure public safety and good GMOs governance. Since commercialization of GM crops alarming studies about the safety of GMOs have been reoccurring and recycling with similar players, arguments and strategies [13] inspite of mounting scientific evidence refuting same.

For instance, refuting the alarming study by Séralini et al. [20] which claimed that rats fed with GM maize were more likely to develop more and more serious tumours in live than those fed with conventional maize, Mampuys and Brom [13] indicated that results of many reviews of Séralini and his team work by many national authorities and scientific bodies concluded that the study contained methodological shortcomings and that the conclusions could not be justified. Although the study was dismissed as unsound and incorrect by scientific advisory bodies and national authorities [13,15], many anti-GMOs advocates continue to cite Séralini et al. [20] conclusion as a basis for their claim that GM crops are not safe for human consumption.

Therefore to ensure scientific basis of comparison, is to be able to isolate the actual effects as a results of gene modification from the general effect of agricultural production practices. The fact that certain adverse environmental 
effect had been established against GM crops is not enough to call for the ban or delay in its commercialization if it not compared with its conventional counterpart.

\subsubsection{Lack of definition of 'harm'}

The second concern of EASAC [15] have to do with the apparent lack of definition of 'harm' and the lack of consensus on what constitute a tolerable level of harm to the environment and human health. Arguments against the safety of GMOs and its food derivatives are usually plagued with multi-level disagreements on the grounds of definition of harm, scientific basis of tolerably level of harm largely driven by interest-based, value-based, moral and metaphysical aspects $[9,13)$. As a result there is general lack of consensus in assigning value to harm caused by genetically modification within the context of current acceptable effects of conventional agriculture.

Binimelis \& Wickson [21] argues that understanding the impacts of GMOs cultivation requires attentiveness to the operational context of the technology as well as a wide range of actors and potential pathways of harm. As a matter of fact, there is no such thing as totally safe food as all food may contained some inherent or natural occurring contaminants or present contamination by several mycotoxins [22]. This is not to suggest that all foods are dangerous, but only to acknowledge the fact that traces of some levels of such contaminants as toxins and carcinogens are present in everything we eat'. Therefore what is of concern is the level of these harmful contaminants and the extent to which they pose adverse effects to health and wellbeing.

Therefore, whether a food is GM or not there will always be the need to carryout contaminant and toxicity tests to guarantee safety for consumption. Richards [23] asserted that food toxins which cause many illnesses mostly arise from both natural and human sources and that there will always be a need to carry out new or unexpected tests for toxins in foodstuffs, regardless of whether it is from GM or non-GM source.

Before being commercially release, food and feed derived from GM crops undergo extensive safety tests, considering among other things the changes in the composition of the plant as a result of the modification by comparing with their conventional crops with history of safe use [24, 25]. Anderson et al. [24] applied this assessment regime in assessing the composition of forage and grain from GM DP202216 maize and concluded that it is equivalent to non-GM conventional maize (Zea mays L.). Many risk assessments of GM crops have applied this method [24, 32, 33].

In all these tests the underlying basis is to establish whether the composition of a GM food, altered by modification, fall within the substantial equivalence level as that of conventional crops [34,16]. Therefore going forward in the GM debate, public interest will be better served in having consensus in the interpretation of results of impact assessments of GMOs on human health and the environment with the view of bring clarity in ascertaining whether the risks associated with GM crops and their food derivatives fall within tolerably limits in comparison with their conventional crops counterpart. Such risk assessment regime referred to as 'substantial equivalence' had been forcefully made and scientific proven. Because conventional food and feed have history of safe use therefore results of risk assessment test of GM crops are interpreted by using the non-GM counterpart as reference. If GM food is found to be substantially equivalent to its conventional counterpart then any argument against its consumption on the basis of safety is nonstarter because its conventional counterparts have history of safe use.

Notwithstanding, after decades of commercialization, GM technology continue to generate controversy inspite of the fact that GM crops and food derivatives are being subjected to rigorous risk assessment procedures and are put under relatively strict safety regularity standards across many countries. Various countries have developed different GM regulatory regimes based on their risk frames, institutional arrangements, and participation modes [25].

I therefore argue that the controversy over safety of GM crops should not be merely over the existence or otherwise of environmental and health risks, because every agricultural practice and product have some level of impact on the environment and some level of risks to human health in one way or the other. Public interest and policy will be better served if there is standardization regarding what constitute tolerably level of harm to the environment and acceptable safety limit in interpreting impact assessment results of GMOs. It is therefore clear that the argument against GM crops on the ground of health and environmental risks is over hyped, speculative and precautionary with the motive of generating negative public perceptions and opinions against GMOs.

\subsubsection{GM crops need to be incorporated with other agricultural practices}

The third conceptual issue as pointed out by EASAC [15] is that GM crops need to be incorporated with other technologies or practices in sustainable management systems, because technology does not operate in isolation. No agricultural technology operates in isolation but rather function within the production system by boasting and 
complementing other elements and players in the system. Binimelis \& Wickson [21] observed that to adequately harnessed the potential of GM crop cultivation require proper interpretation of impacts assessment results by paying attention to the operational context of the technology as well as a wide range of actors and potential pathways of harm.

For instance, initial reports attributed the erosion of glyphosate efficacy and emergence of supperweeds to gene flow from herbicide tolerant Roundup- Ready (RR) GM crops [26, 27] which was later found to be caused by poor agronomic practices. Similarly, Helander et al. [28] review of erosion of glyphosate efficacy found that it is cause by poor crop management procedures, not GM-specific technology as it was initially thought of. Also, the argument that transgenes toxins from Bt trait GM crops might cause ecological imbalances by influencing population levels of competitors, preys, hosts, symbionts, predators, parasites, and pathogens [27, 29] can also be argued with regard to conventional agriculture in which pesticide are widely used and cannot entirely be blamed on GM specific technology.

Therefore, it is essential that suitable agronomic practices are put in place to maximise the benefit that can be derived from agricultural innovation while minimising any potential adverse effects it may pose to human health and the environment. It will be therefore necessary that going forward emphasis on discussions on GM crops should not merely be whether GM crops pose some risks to human health and environment, but rather focus on formulating scientific and agricultural policies required to ensure that the potential value of GM technology is safely harnessed for increase agricultural productivity while ensuring its negative consequences are curtail through institutional and regulatory frameworks. Also strengthening risk assessment regimes and early warning mechanisms in the production, safe handling, transfer and consumption of GM products is critical in gaining public trust and confidence on GMOs regulatory frameworks and standards.

\subsection{Food Sovereignty argument}

Grave concerns of anti-GM activists, especially in developing countries, is the fear of multinational corporate control of local agricultural production and food supply through the arrangement of seed patents associated with commercialization of GMOs. As observed by Katiraee [30] that the common criticism of GM foods is that their seeds are patented to developers who are mostly profit motivated multinational corporations. Leonelli [35] study's on the dominant regulatory approach to the governance of GMO risks argued that although GMOs are identified as a strategy to tackling food insecurity and facilitating climate change adaptation, the patenting and trade regime of GM seeds serve the profit-making goals of transnational market actors. Naylor [36] also argues that due to political, corporate trusteeship, profit - driven and knowledge - enclosure behind most GMO production there is no place for GMOs in food sovereignty. He further argues that since food sovereignty is about changing conditions which creates inequalities in the food system a narrow focus of corporations' profit - driven motives through GMO production tends to reinforces these inequalities [36].

The ultimate goal of Intellectual Property Right (IPR) or patents regime associated with trade of GM seeds is to provide benefits to stakeholders and, ultimately the general public through providing legal protection for investment into GM research. Achieving this goal depends upon balancing the possibility of reward to the developer with benefits that can then flow to others. While not necessarily providing a "silver-bullet," the availability of effective IPR regime is an important component of business decisions affecting research and product development [37].

Garzón and Escobar [38] in their paper 'resisting multinational seed corporations and legal seed regimes through seed-saving practices and activism in Colombia' observed that difference categories of farmers have diverse ways of resisting seed sovereignty expressed by their seed saving strategies. They demonstrated that indigenous farmers' seed saving strategy represents a form of resistance mobilized through narratives of tradition, sovereignty, freedom, and environmental protection while industrial farmers, who grow genetically-modified cotton, carry out seed saving surreptitiously to minimize production costs and to resist the enclosure of seeds by corporations.

The nature of patents regimes associated with commercialization of GM crops is fuelling the fears that biotechnology industry which is driven by few corporations with monopolistic power will eventually take over the seed market and therefore pose a threat to national food sovereignty [31]. Anti-GM activists have vehemently argued against the patents regimes governing GM seeds, describing it as an attempt to control global food production by few corporations with the tendency of creating a situation where resource poor farmers will have to perpetually depend on biotech companies for their seeds. Such, a situation, they claimed will further worsen the poverty levels of smallholder farmers and food insecurity situation of developing countries [39]. Similarly, Bhuiya [40] noted that, the advent of GM crops may shift local control and farming system to corporate control and thereby making global food production subject to international politics and geopolitical manipulation. There is the fear that seeds local farmers 
have been using over the years will give way to genetically modified seeds and then becomes the property of biotech corporate multinationals by patents. Such control, anti-GM advocates warned, will eventually alters farmers' ownership and control over seeds generation and use and thereby leading to the enslavement of local farmers to multinational biotech companies [40,39]. Traditionally, farmers select portion of their harvest and store them as seed for the next season, and practice plant improvement by selecting and exchanging seeds with one another and this give them ownership right over their seeds and as such put them in charge of growing their own food.

The possible shift in locally controlled farming system and food production to multinational corporate controlled in the cultivation of GM crops, is being argued within the wider scope of political economy with conspiracy theory of geopolitical manipulation of national food sovereignty. The conspiracy is that farmers in developing countries are likely to lose autonomy in their staple food production to profit driven biotech companies. Which eventually will torpedo locally control over food production and supply and thereby giving biotech multinational companies totally dominance in food production through seed supply and this can be used as tool to manipulate global politics.

However, these fears and conspiracy theories have adequately been responded to by proponents of GM technology. For instance, Katiraee [30] drew the attention of anti-GM activist to the fact that seeds from genetically modified crops are not the only ones that are patented. He cited the many conventionally bred crops which are patented under the US Patents and Trademark Office as evidence that patents is not a feature inherent with GMOs. The argument against GMOs patents legislative regime might be appealing to skeptics, but it failed to acknowledge and provide alternatives for funding the huge investment required in breeding and developing GM seeds.

Considering the time, money and effort spent in crop breeding, either genetic modification or the conventional breeding methods, it makes sense for private developers to protect their investment through patents regulatory regime. For instance, a survey of six companies on the cost of GM crop traits revealed that the mean cost associated with the discovery, development and authorisation of a new biotechnology derived crop trait introduced in the 20082012 timeframe is $\$ 136$ million [30]. In addition, the study further revealed that the discovery accounted for an estimated $22.8 \%$ and $23 \%$ of total cost and time involved respectively. While regulatory science, registration and regulatory affairs being the longest single phase in product development and is estimated to account for $25.8 \%$ and $36.7 \%$ of total cost and time involved respectively (ibid).

Such heavy investment needs to be paid for and safeguarded so as to attract and assure private investors who are willing to invest in crop improvement and seed marketing. Patents regimes and institutional frameworks put in place to ensure the protection of investment of biotech companies and to motivate private investment in biotechnology research, had been lauded as the most robust and reliable arrangement in securing investment in biotechnology research whiles ensuring the development of crops with the desire traits for sustainable agricultural development. These patents are protected through the World Trade Organization (article 27) and the International Union for the Protection of New Varieties of Plants (also known as UPOV) which member nations are expected to rectify and implement through the enactment of specific domestic laws and legislations [30].

Therefore, the debate on whether or not these patents should exist in the first place is outside the scope of the GMO discussion and should be directed towards how best to attract and safeguard the huge investment required in producing successful GM seed. Public investment into research and development is purely public policy decision and priority of national governments. If national public investment into research in agrobiotechnology can provide for the require investment, expertise and capacity needed to develop GM crops, the issue of corporate takeover of national food sovereignty will not arise. If national governments are committed to investing public resources on agrobiotechnology research as it is done in China and India [31], then the fear of corporate dominance and possible control of global food production will not arise. As such the debate on GM crops within the context of political economy regarding control on biotechnology research and seed market, should rather focus on discussions on choices of national government in biotechnology research capacity and investment and their regulatory and legal regimes regarding patents of genetically modified seeds.

Also Public Private Partnerships (PPP), between national governments and biotech industries have been noted as an effective way of improving access to biotechnology research for the improvement of staple food crops varieties for smallholder farmers in developing countries, especially Africa. As asserted by Chambers et al. [41] that PPPs had become increasingly prevalent in many African countries with the goal of ensuring that private research on GM crops is combined with local knowledge of varieties and cropping conditions that resides in public research organizations in order to develop GM crops suitable to Africa conditions. There are several successful examples of public-private partnerships which have facilitated access to biotechnology and development of improved crop varieties for developing countries. For instance, the transferred of golden rice, which is genetically modified to produce $\beta$-carotene 
the precursor to vitamin A, to developing countries particularly Philippines, India, China, Vietnam and Indonesia under PPPs is a clear demonstration of the effectiveness of PPP arrangement in improving smallholders farmers access to GM technology [41].

\section{Conclusion and recommendations}

Critical scrutiny of anti-GM activists' narratives regarding the possible health risk associated with GM food reveals a wide array of precautionary, skepticism and fear-mongering with the motive of generating public disapproval and rejection of GMOs in food production. As much as caution is necessary as it lead to the formulation of proactive biosafety measures to prevent the occurrence of negative consequences which might be harmful to human health and the environment, presenting it as empirical fact is deliberate distortion and misleading, to the say the least.

Analysis of available literature reveals that the GM debate had suffered from several conceptual problems and lack of standardization in interpreting impact assessment results. Public interest and policy will be better served if there is standardization regarding what constitutes tolerable level of harm to the environment and acceptable safety limits in interpreting impact assessment results of GMOs.

Regarding the argument of threat to food sovereignty, many anti-GM activists have vehemently argued against the patents regimes governing GM seeds, describing it as an attempt to control global food production by few corporations with the tendency of creating a situation where resource poor farmers will have to perpetually depend on biotech companies for their seeds. But the fact that other conventional bred seeds also have patents and protected by intellectual property right, takes the argument of patents regime creating corporate control of the global market with consequence on national food sovereignty out of the GM debate. Therefore, the debate on whether or not these patents should exist in the first place is outside the scope of the GMO discussion and should be directed towards how best to attract and safeguard the huge investment required in producing successful GM seed.

\section{Compliance with ethical standards}

\section{Acknowledgments}

My profound gratitude goes to UDS library for providing me access to on-line academic resources which had assisted me in carrying this review.

\section{References}

[1] Ali A and Rahut DB. (2018).Farmers willingness to grow GM food and cash crops: empirical evidence from Pakistan. GM Crops \& Food, 9(4), 199-210.

[2] ISAAA. (2018). Global Status of Commercialized Biotech/GM Crops in 2018: Biotech Crops Continue to Help Meet the Challenges of Increased Population and Climate Change. ISAAA Brief No. 54.

[3] Raman R. (2017). The impact of Genetically Modified (GM) crops in modern agriculture: A review. GM Crops \& Food, 8(4), 195-208.

[4] Glaab K and Partzsch L. (2018). Utopia, Food Sovereignty, and Ethical Fashion: The Narrative Power of antiGMO Campaigns. New Political Science, 40(4), 691-707.

[5] Shilomboleni H. (2018). African Green Revolution, food sovereignty and constrained livelihood choice in Mozambique. Canadian Journal of African Studies/Revue canadienne des études africaines, 52(2), 115-137.

[6] Brookes G and Barfoot P. (2019). Global Benefits Benefits \& Safety of Biotechnology Database. Crop Life International.

[7] ISAAA. (2016). Global Status of Commercialized Biotech/GM Crops: 2016. ISAAA Brief No. 52.

[8] ISAAA. (2017). Biotech Crop Adoption Surges as Economic Benefits Accumulate in 22 Years. Global Status of Commercialized Biotech/GM Crops in 2017: ISAAA Brief No. 53.

[9] Brookes G and Barfoot P. (2018) Environmental impacts of genetically modified (GM) crop use 1996-2016: Impacts on pesticide use and carbon emissions. GM Crops \& Food, 9(3), 109-139. 
[10] Vigani M and Olper A. (2014). GM-free private standards, public regulation of GM products and mass media. Environment and Development Economics, 19(6), 743-768.

[11] Gilbert N. (2013). A hard look at GM crops. Nature, 497, 24-26.

[12] Nicolia A, Manzo A, Veronesi F and Rosellini D. (2014). An Overview of the Last 10 Years of Genetically Engineered Crop Safety Research. Crit Rev Biotechnol, 34(1), 77-88.

[13] Mampuys R and Brom FWA. (2015). Governance strategies for responding to alarming studies on the safety of GM crops. Journal of Responsible Innovation, 2(2), 201-219.

[14] Pearsall D. (2013). GM crop co-existence. GM Crops \& Food, 4(3), 143-150.

[15] EASAC (2013). Planting the future: opportunities and challenges for using crop genetic improvement technologies for sustainable agriculture. European Academies Science Advisory Council policy report.

[16] Qaim M. (2015). Genetically Modified Crops and Agricultural Development. Copyright (C) Martin Qaim. Printed by Hardcover ISBN 978-1-137-40571-5

[17] Biden S, Smyth SJ and Hudson D. (2018). The economic and environmental cost of delayed GM crop adoption: The case of Australia's GM canola moratorium. GM Crops \& Food, 9(1), 13-20.

[18] Brookes G and Barfoot P. (2017). Environmental impacts of GM crop use 1996-2015: impacts on pesticide use and carbon emissions. GM Crops. 8(2), 117-147.

[19] Brookes G. (2017). The potential socio-economic and environmental impacts from adoption of corn hybrids with biotech trait/technologies in Vietnam. PG Economics, UK.

[20] Séralini GE, Claira E, Mesnage R, Gress S, Nicolas Defarge N, Malatesta M et al. (2012).Long Term Toxicity of a Roundup Herbicide and a Roundup-Tolerant Genetically Modified Maize. Food and Chemical Toxicology, 50(11), 4221-4231.

[21] Binimelis R and Wickson F. (2019). The troubled relationship between GMOs and beekeeping: an exploration of socioeconomic impacts in Spain and Uruguay. Agroecology and Sustainable Food Systems, 43(5), 546-578.

[22] Khaneghah MA, Eş I, Raeisi S and Fakhri Y. (2018). Aflatoxins in cereals: State of the art. Journal of Food Safety. $38(6)$.

[23] Richards A. (2017). Quality Assurance and Control for Accurate Measurement of Food Toxins: In Wong Y and Lewis J.R. (Eds), Analysis of Food Toxins and Toxicants. John Wiley \& Sons Ltd.

[24] Anderson JA, Hong B, Moellring E, TeRonde S, Walker C, Wang Y and Maxwell C. (2019). Composition of forage and grain from genetically modified DP202216 maize is equivalent to non-modified conventional maize (Zeamays L.). GM Crops \& Food, 10(2), 77-89.

[25] Salazar MP, Valenzuela D, Tironi M and Gutiérrez RA. (2019). The ambivalent regulator: the construction of a regulatory style for genetically modified crops in Chile. Tapuya: Latin American Science, Technology and Society, 2(2), 212-221.

[26] Lang, A and Otto M. (2010). A synthesis of laboratory and field studies on the effects of transgenic Bacillus thuringiensis (Bt) maize on non-target Lepidoptera. Entomologia Experimentalis et Applicata, 11(5), $121-134$.

[27] Zobiole LHS, Kremer RJ, Oliveira RS and Constantin J. (2011). Glyphosate affects microorganisms in rhizospheres of glyphosate-resistant soybeans. Journal of Applied Microbiology, 110(2), 118-127.

[28] Helander M, Saloniemi I and Saikkonen K. (2012). Glyphosate in northern ecosystems. Trends in Plant Sciences, 17(5), 569-574.

[29] Binimelis R, Pengue W and Monterroso I. (2009). "Transgenic treadmill": Responses to the emergence and spread of glyphosate resistant Johnson grass in Argentina. Geoforum, 40, 623-633.

[30] Katiraee L. (2014). Patents and GMOs: Should biotech companies turn innovations over to public cost-free? Genetic Literacy Project publication.

[31] Fukuda-Parr S and Orr A (2012). GM Crops for Food Security in Africa -The Path Not Yet Taken. United Nations Development Programme (UNDP) working paper. WP 2012-018.

[32] Baktavachalam GB, Delaney B, Fisher TL, Ladics GS, Layton RJ, Locke MEH, Schmidt J, Anderson JA, Weber NN, Herman RA and Evans SL. (2015). Transgenic maize event TC1507: Global status of food, feed, and environmental safety. GM Crops \& Food, 6(2), 80-102. 
[33] Herman RA, Phillips AM, Lepping MD, Fast BJ and Sabbatini J. (2010). Compositional safety of event DAS40278-9 (AAD-1) herbicide-tolerant maize. GM Crops, 1(5), 294-311.

[34] Davison J and Ammann K. (2017). New GMO regulations for old: Determining a new future for EU crop biotechnology. GM Crops \& Food, 8(1), 13-34.

[35] Leonelli GC. (2019). GMO risks, food security, climate change and the entrenchment of neo-liberal legal narratives. Transnational Legal Theory, 9 (3-4), 302-315.

[36] Naylor L. (2017). A Place for GMOs in Food Sovereignty? Geographical review, 107(4), 572-577.

[37] Smith S. (2019).The Foundations, Continuing Evolution, and Outcomes from the Application of Intellectual Property Protection in Plant Breeding and Agriculture. Plant Breeding Reviews, 43.

[38] Garzón DS and Escobar LG. (2019). Revolturas: resisting multinational seed corporations and legal seed regimes through seed-saving practices and activism in Colombia. The Journal of Peasant Studies, 46(7).

[39] Specter, M. (2014). Seeds of Doubt An activist's controversial crusade against genetically modified crops. Annals of Science, 4(2).

[40] Bhuiya SN. (2012). Ethical Concerns in Development, Research and Consumption of Genetically Engineered Crops. Synesis: A Journal of Science, Technology, Ethics, and Policy 2012 (C) 2010-2012 Potomac Institute Press.

[41] Chambers JA, Zambrano P, Felick-Zepada J, Gruere G, Sengupta D and Hokason K. (2014). GM Agricultural Technologies for Africa: A state of Affairs. International Food Policy Research Institute (IFPRI) and African Development Bank (AfDA).

\section{How to cite this article}

Zakaria H. (2020). Drivers of the various stands on the debate on GM crops: What are the real motives beyond the public rhetoric? GSC Advanced Research and Reviews, 2(3), 09-17. 